ARTICLE

https://doi.org/10.1038/s41467-019-08448-y

\title{
A cell-free platform for the prenylation of natural products and application to cannabinoid production
}

\author{
Meaghan A. Valliere', Tyler P. Korman', Nicholas B. Woodall ${ }^{1}$, Gregory A. Khitrov ${ }^{1}$, Robert E. Taylor ${ }^{1}$, \\ David Baker (iD ${ }^{2} \&$ James U. Bowie ${ }^{1}$
}

Prenylation of natural compounds adds structural diversity, alters biological activity, and enhances therapeutic potential. Because prenylated compounds often have a low natural abundance, alternative production methods are needed. Metabolic engineering enables natural product biosynthesis from inexpensive biomass, but is limited by the complexity of secondary metabolite pathways, intermediate and product toxicities, and substrate accessibility. Alternatively, enzyme catalyzed prenyl transfer provides excellent regio- and stereo-specificity, but requires expensive isoprenyl pyrophosphate substrates. Here we develop a flexible cell-free enzymatic prenylating system that generates isoprenyl pyrophosphate substrates from glucose to prenylate an array of natural products. The system provides an efficient route to cannabinoid precursors cannabigerolic acid (CBGA) and cannabigerovarinic acid (CBGVA) at $>1 \mathrm{~g} / \mathrm{L}$, and a single enzymatic step converts the precursors into cannabidiolic acid (CBDA) and cannabidivarinic acid (CBDVA). Cell-free methods may provide a powerful alternative to metabolic engineering for chemicals that are hard to produce in living organisms.

\footnotetext{
${ }^{1}$ Department of Chemistry and Biochemistry, Molecular Biology Institute, UCLA-DOE Institute, University of California, Los Angeles 90095 CA, USA.

${ }^{2}$ Department of Biochemistry, Institute for Protein Design, University of Washington, Seattle 98105 WA, USA. Correspondence and requests for materials should be addressed to J.U.B. (email: bowie@mbi.ucla.edu)
} 
P renylated natural products are a large class of bioactive molecules with demonstrated medicinal properties ${ }^{1}$. Examples include prenyl-flavanoids, prenyl-stilbenoids, and cannabinoids (see Fig. 1). Cannabinoids in particular sho$\mathrm{w}$ immense therapeutic potential with over 100 ongoing clinical trials as antiemetics, anticonvulsants, antidepressants, and analgesics ${ }^{2-6}$. Nevertheless, despite the therapeutic potential of prenyl-natural products, their study and use is limited by the lack of cost-effective production methods. Plant-derived prenylcompounds are difficult to isolate due to the structural similarity of contaminating molecules, and the variable composition between $\mathrm{crops}^{7,8}$. These challenges are further exacerbated when attempting to isolate low abundance compounds. Many chemical syntheses have been developed to address the challenges associated with making prenylated natural products, but they are generally impractical for drug manufacturing due to the degree of complexity and low yields ${ }^{9-11}$.

Microbial production is a useful alternative to natural extraction for prenylated natural products, but comes with many challenges such as the need to divert carbon flux from central metabolism and product toxicity to name a few. For example, prenyl-natural products like prenyl-naringenin, prenyl-resveratrol, and cannabidiol (CBD) are derived from a combination of the metabolic pathways for fatty acid, isoprenoid, and polyketide biosynthesis. So, high-level production requires efficient rerouting of long, essential and highly regulated pathways. Despite the challenges, many groups have engineered microbes to produce unprenylated polyketides, like naringenin, resveratrol, and olivetolate, but at relatively low levels $(110,391$, and $80 \mathrm{mg} / \mathrm{L}$, respectively) ${ }^{12,13}$. Obtaining prenylated products is even more challenging because geranyl-pyrophosphate (GPP) is an essential metabolite that is toxic to cells at moderate concentrations, creating a significant barrier for high-level microbial production $^{14}$. So, in spite of intense interest, to our knowledge there are no published reports of the complete biosynthesis of prenylflavonoids, prenyl-stilbenoids, or cannabinoids in recombinant microbes.

Much recent effort has focused on alternative methods for cannabinoid production. Two groups have produced the polyketide cannabinoid intermediate, olivetolic acid $(\mathrm{OA})$ at low levels in yeast $(0.5 \mathrm{mg} / \mathrm{L})$ or $E$. coli $(80 \mathrm{mg} / \mathrm{L})$, but did not prenylate OA or produce a cannabinoid from the biosynthesized $\mathrm{OA}^{13,15}$. In other work, tetrahydrocannabinolic acid was produced in cell extracts from either exogenously added GPP and OA in a two enzyme pathway ${ }^{16}$ or from cannabigerolic acid (CBGA) using a single enzyme ${ }^{17}$. However, it is unclear how GPP or CBGA could be obtained at sufficient levels for economical production due to the high cost of these molecules.

Here, we propose an alternative biological approach to prenylated natural product biosynthesis using a cell-free enzymatic platform we call synthetic biochemistry, which has shown great promise for the production of bio-based molecules ${ }^{18-24}$. The synthetic biochemistry approach frees us from worrying about the toxicity of products and intermediates, affords rapid designbuild-test cycles, precise control of all system components, and complete flexibility in pathway design. Nevertheless, building highly complex systems involving dozens of enzymes, associated cofactors and myriad metabolites on a large scale outside the context of the cell is an enormous challenge. One of the keys to making commercially viable cell-free systems is reducing enzyme costs by employing stable enzymes that can last for long periods of time. Recently, Zhang and co-workers converted maltodextrin into inositol at a 20,000 L scale in a five enzyme system using thermophilic enzymes purified by simple heating step ${ }^{25}$, demonstrating that at least simple cell-free systems can reach industrial scale. Another key requirement is designing systems

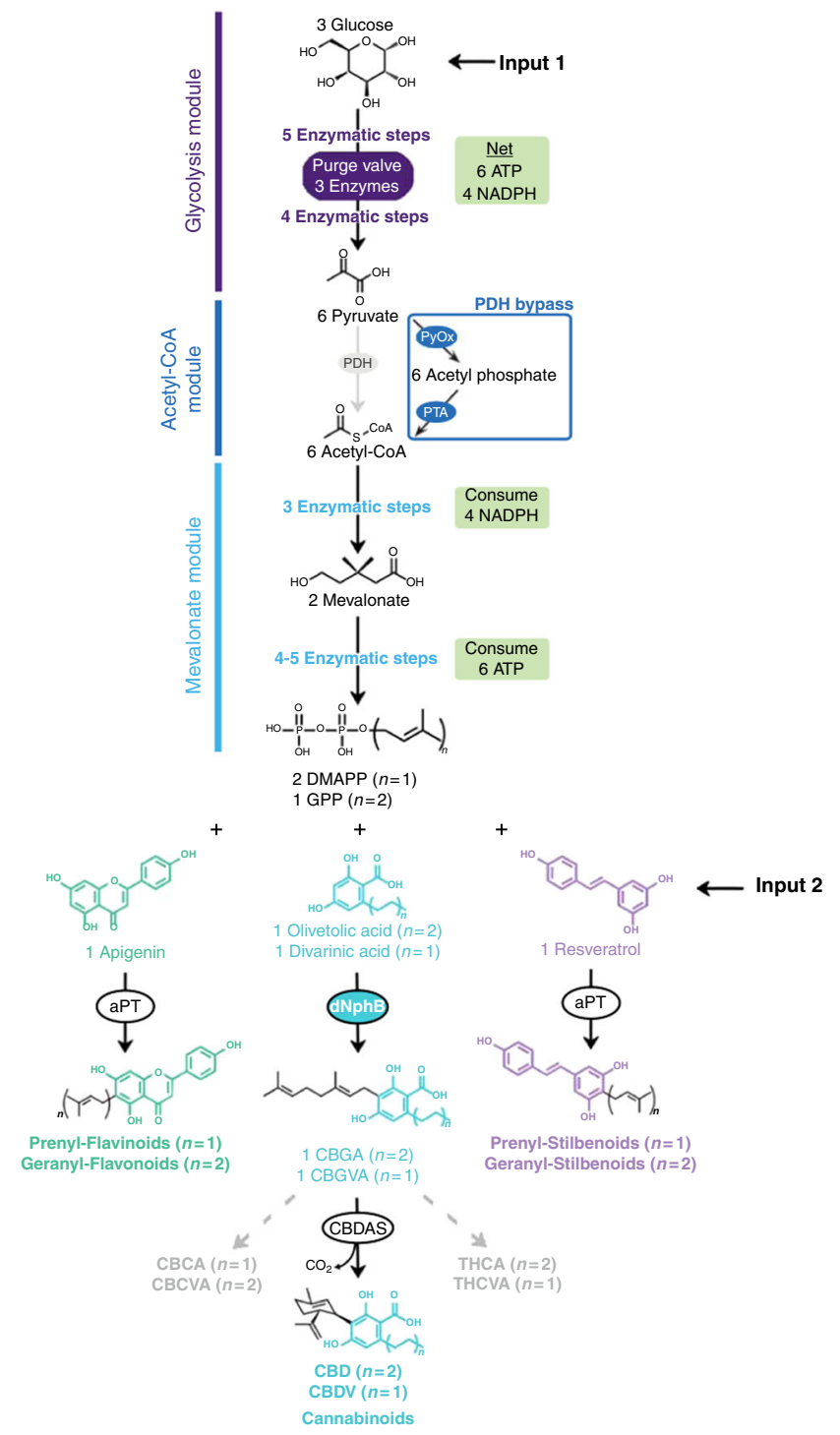

Fig. 1 The synthetic biochemistry platform for the production of prenylnatural products. First, glucose is broken down into pyruvate through a glycolysis pathway modified to regulate NADPH levels (22) (12 enzymatic steps). Then, either PDH or the PDH bypass converts pyruvate into acetylCoA. Acetyl-CoA is converted into GPP via the mevalonate pathway (eight enzymatic steps). By varying the aromatic prenyltransferase (aPT) and aromatic substrate we are able to produce various prenyl-flavonoids and prenyl-stilbenoids using the same central pathway. We developed variants of the prenyltransferase NphB ( $\mathrm{dNphB}$ ) to produce CBGA or CBGVA. CBGA is converted to cannabidiol and CBGVA is converted to cannabidivaric acid via cannabidiolic acid synthase (CBDAS). It is possible to produce other cannabinoids by using different cannabinoid synthases (THCAS and CBCAS)

that effectively generate and recycle high energy cofactors (ATP, $\mathrm{NAD}(\mathrm{P}) \mathrm{H})$ so that they can be used many times. We have previously reported a flexible enzymatic purge valve and rheostat for regulating the supply of reducing equivalents and $\mathrm{ATP}^{26-28}$, allowing us to build systems that run for many days and produce high titers of isobutanol and terpenes. Here, we employ these concepts to develop cell-free production of a variety of prenylated compounds. We use glucose as a feedstock to produce GPP and optimize the system for the high-titer production of the cannabinoid compounds $\mathrm{CBGA}$ and cannabigerovarinic acid (CBGVA). 


\section{Results}

Construction of the cell-free prenylation pathway. Our synthetic biochemistry approach is outlined in Fig. 1 (detailed in Supplementary Figure 1) and expands on a system we developed previously for terpene production ${ }^{26}$. First, glucose is broken down via a modified glycolysis pathway to produce high-energy cofactors ATP and NADPH in addition to the carbon building block, acetylCoA using an alternative pyruvate oxidation pathway ${ }^{26}$. The acetyl-CoA is then assembled into the prenyl-donor compound, GPP, via the mevalonate pathway using the ATP and NADPH produced from glycolysis. Importantly, a purge valve ${ }^{26}$ introduced into the glycolysis pathway balances $\mathrm{NADPH}$ production and consumption while maintaining carbon flux. The prenylation module then uses the GPP to prenylate exogenously added substrate to yield the desired prenylated product. To expand the capabilities of our synthetic biochemistry platform we developed a prenylating system that employs a nonspecific prenylating enzyme such as $\mathrm{NphB}$, AtaPT, or NovQ to produce an array of prenyl-compounds derived from glucose ${ }^{29-31}$. We then further engineered NphB using Rosetta to specifically prenylate OA.

As a first test of the system, we built the full cell-free system (23 enzymes) to generate GPP from glucose and employed wildtype NphB to prenylate its preferred substrate 1,6 dihydroxynapthalene (1,6 DHN; added exogenously). 1,6 DHN was added at the beginning of the reaction along with glucose. Up to $\sim 400 \mathrm{mg} / \mathrm{L}(1.3 \mathrm{mM})$ of prenylated product was obtained from $2.5 \mathrm{mM} 1,6 \mathrm{DHN}$. However, increasing the 1,6 DHN concentration from 2.5 to $5 \mathrm{mM}$, decreased final titers $\sim 2$-fold suggesting that 1,6 DHN inhibited one or more enzymes (Fig. 2a). Enzyme assays revealed that pyruvate dehydrogenase $(\mathrm{PDH})$ was inhibited by 1,6 DHN, as well as olivetol, resveratrol, and olivetolate (Fig. 2b). Therefore, to engineer a general prenylation system, we sought to eliminate $\mathrm{PDH}$.

To remove the need for $\mathrm{PDH}$, we implemented a $\mathrm{PDH}$ bypass (Fig. 1). In the PDH bypass, pyruvate is converted to acetyl-CoA using a pyruvate oxidase (PyOx) to produce acetyl-phosphate
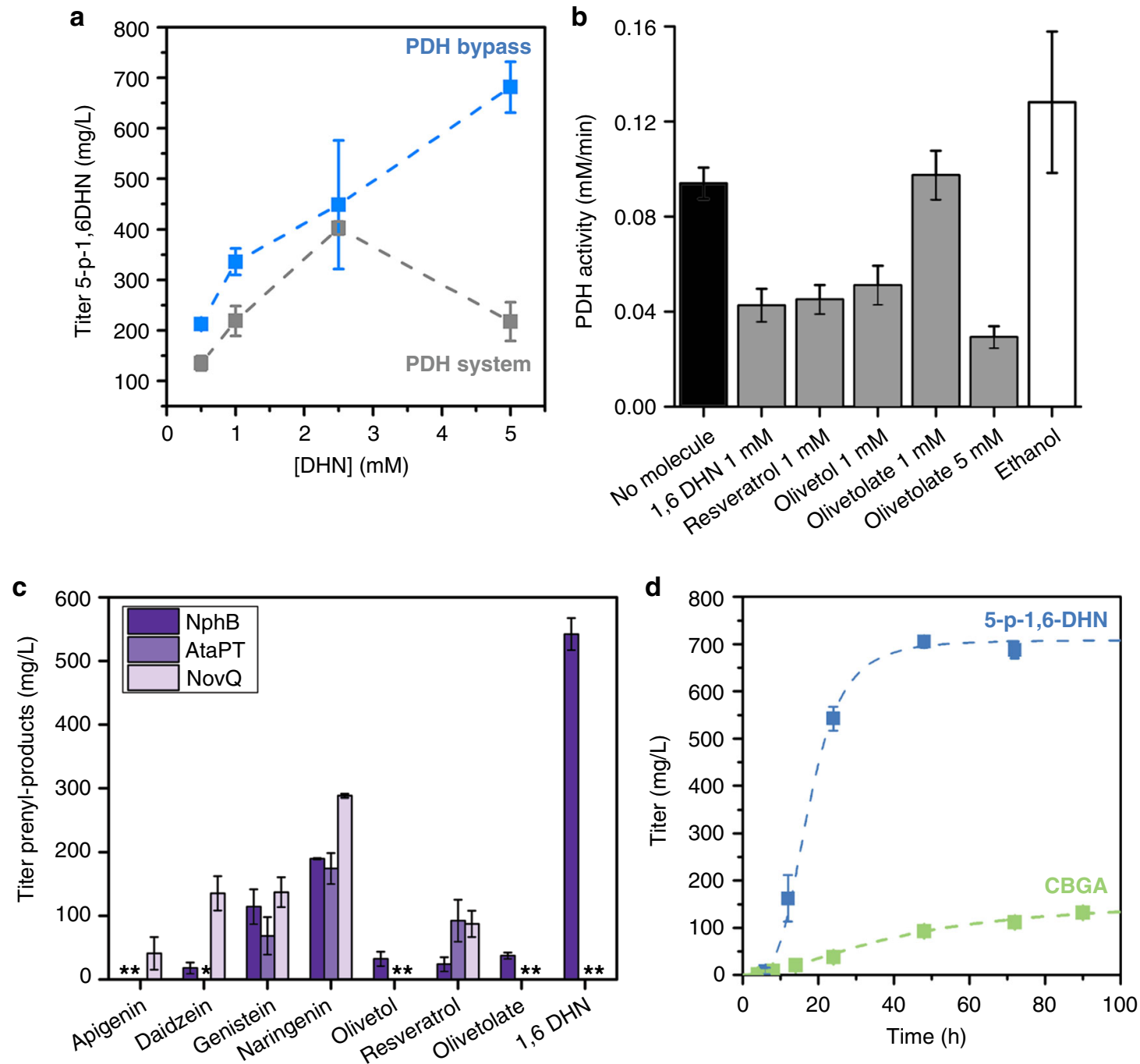

Fig. 2 Development of a PDH bypass for the prenylation of aromatic polyketides. a The comparison of the final titers achieved with the full pathway utilizing $\mathrm{PDH}$ (PDH system-gray trace) and the PDH bypass system (blue trace) at different concentrations of 1,6 DHN. (biological replicates, $n=3$ ). $\mathbf{b}$ The activity of pyruvate dehydrogenase (E. coli PDH) measured in the presence of various aromatic polyketides and $2 \%$ ethanol (vehicle) (biological replicates, $n=3$ ). c Various aromatic substrates were added to the pathway with either NphB, AtaPT, or NovQ prenyltransferase (biological replicates, $n=3$ ). The result is a variety of C5 and C10 prenyl-natural products. ( ${ }^{*}$ Indicates titer not determined). d Production of 5-prenyl-1,6 DHN (blue trace) over time compared to a separate reaction to produce CBGA (green trace). Both reactions utilized the PDH bypass and WT NphB (biological replicates, $n=3$ ). All error ranges reflect the standard deviation. Source data for Fig. 2a-d are provided as a Source Data file 
a

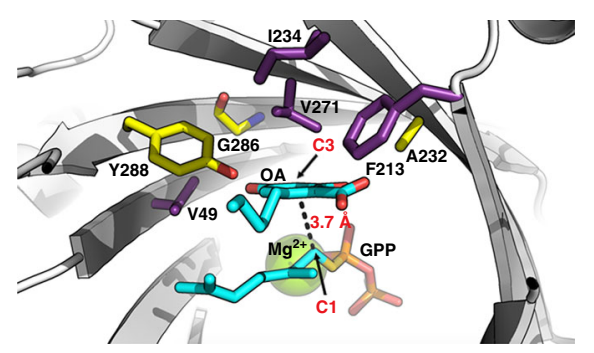

b

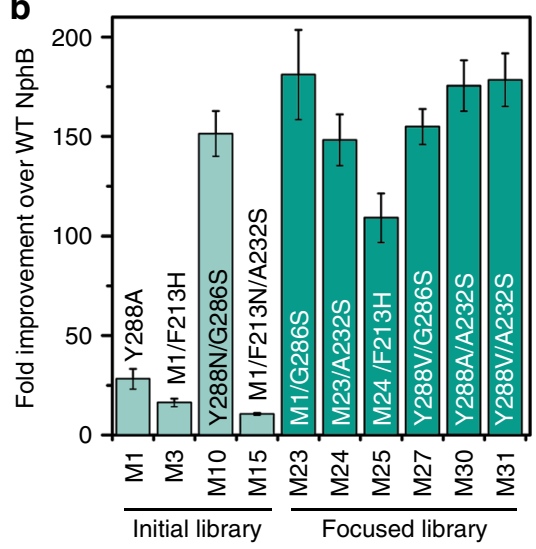

c

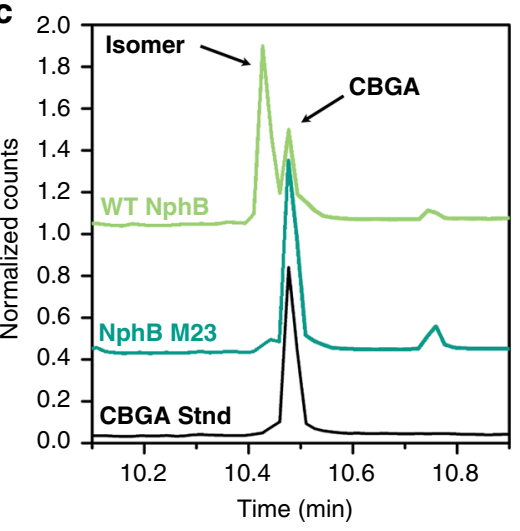

Fig. 3 Engineering NphB to improve CBGA production. a A model of olivetolate in the active site of WT NphB (1ZB6). Residues highlighted in yellow and purple were allowed to vary during the design process. The residues in yellow had the largest effects on activity with OA and were the positions targeted in the focused library. $\mathbf{b}$ The results of an activity assay to determine the approximate activity of NphB mutants with olivetolate as the substrate. The fold improvement is an average of triplicate reactions with GPP $(2.5 \mathrm{mM})$, olivetolate $(5 \mathrm{mM}), \mathrm{MgCl}_{2}(5 \mathrm{mM})$, and $1 \mathrm{mg} / \mathrm{mL}$ of WT or mutant NphB (biological replicates, $n=3$, error range is standard deviation). c GC-MS chromatograms of the full pathway reaction products using M23 or WT NphB compared to a CBGA standard. Source data for Fig. 3b, c are provided as a Source Data file

followed by the action of acetyl-phosphate transferase (PTA). The PDH bypass has two advantages. First, PDH is a large enzyme complex that is difficult to work with, so bypassing PDH streamlines enzyme production. More importantly, initial experiments revealed that the bypass is not subject to the inhibition seen at higher concentrations of 1,6 DHN. Once we confirmed the PDH bypass improved 1,6 DHN titers, we began to optimize the system as a general prenylation system. We varied co-factor concentrations, protein levels, and environmental conditions such as temperature and $\mathrm{pH}$ to identify the ideal set of conditions. Throughout this process we found that ATP, NADP + , phosphate, and $\mathrm{NphB}$ concentrations had the greatest impact on the final titer. As shown in Fig. 2a, when we employed the PDH bypass, we found a 4-fold increase in titers of 5-prenyl-1,6 DHN when starting with $5 \mathrm{mM} \mathrm{1,6} \mathrm{DHN} \mathrm{(Fig.} \mathrm{2a).} \mathrm{When} \mathrm{utilizing} \mathrm{the} \mathrm{PDH}$ bypass system, approximately $50 \%$ of $1,6 \mathrm{DHN}$ was converted in $24 \mathrm{~h}$, reaching a final titer of $705 \pm 12 \mathrm{mg} / \mathrm{L}$ (all error ranges in this work reflect the standard deviation) (Fig. 2b).

We then tested the ability of the PDH bypass cell-free system to prenylate a variety of aromatic substrates (apigenin, diadzein, genestein, naringenin, olivetol, $\mathrm{OA}$, and resveratrol). All the aromatic substrates were prenylated using one or more of the tested prenyl transferases (Fig. 2c and Supplementary Figures 5-10). Thus, it is possible to produce a variety of prenylated natural products using a cell-free enzymatic system to generate the expensive co-substrates GPP and DMAPP. Further, the ease with which an exogenous substrate can be added to a synthetic biochemistry system is a great advantage because it is often not possible to add co-substrates exogenously to microbes since they cannot enter the cell ${ }^{16}$.

To test whether we could use synthetic biochemistry to produce high levels of therapeutically relevant prenylated products, we focused optimization efforts on cannabinoids due to the growing interest in new ways to make these medically important compounds. As shown in Fig. $2 \mathrm{~d}$ the initial system produced the cannabinoid precursor CBGA at a constant rate of $2.1 \mathrm{mg} \mathrm{L}^{-1} \mathrm{~h}^{-1}$ over $72 \mathrm{~h}$ and reached a final titer of only $132 \mathrm{mg} / \mathrm{L}$ (Fig. 2d).

Redesign of NphB to improve CBGA synthesis. Although the system produced CBGA, there were two problems. First, the turnover rate of the prenyltransferase $\mathrm{NphB}$ for CBGA production is extremely poor $\left(k_{\text {cat }}=0.0021 \pm 0.00008 \mathrm{~min}^{-1}\right.$, Supplementary Table 5). Second, prenylation of OA by NphB is highly nonspecific, generating a major side-product, 2-O-geranyl olivetolate ${ }^{16}$. We therefore, sought to improve CBGA production by enhancing the activity and specificity of $\mathrm{NphB}$ by design.

Briefly, OA was docked into the active site of the NphB crystal structure (Fig. 3a) ${ }^{32}$, then Rosetta was used to predict mutations that would improve OA binding. We narrowed the Rosetta results to a 22 construct library (see Supplementary Tables 2 and 3), and screened for CBGA production (Supplementary Table 4). We made several key observations during the initial screen, shown in Supplementary Figure 2: (1) Y288A (M1) and Y288N (M2) by themselves dramatically enhanced activity, as predicted by computation; (2) the presence of $\mathrm{Y} 288 \mathrm{~N}$ in any construct decreased the enzyme yield suggesting $\mathrm{Y} 288 \mathrm{~N}$ may be a destabilizing mutation (making Y288A the preferred mutation); (3) the addition of G286S in the Y288N (M10) background appeared to improve activity further over Y288N (M2), suggesting that G286S could be another favorable mutation; (4) we noted an activity improvement of Y288A/F213N/A232S (M15) over Y288A/F213N (M5) suggesting that A232S may also be a favorable mutation. From these initial observations we constructed a focused library with all but one of the constructs in the second library exhibiting activity at least 100-fold higher than WT $\mathrm{NphB}$ in an endpoint assay (Fig. 3b).

The best two constructs, M23 and M31, exhibited dramatically improved activity and specificity. Both had $k_{\text {cat }}$ values 1000 -fold higher than WT $\mathrm{NphB}$ and both produce only the correct prenylated isomer, CBGA. As shown in Fig. 3c, WT NphB produces $\mathrm{CBGA}$, but the dominant product is a prenylated sideproduct, 2-O-geranyl olivetolate, whereas M23 makes CBGA almost exclusively. Overall, the designed enzyme is a much more active and specific CBGA synthase than WT NphB, and is easier to work with than the natural cannabis prenyltransferase, which is an integral membrane protein ${ }^{16,33}$. Our soluble, CBGA synthase (M23) could potentially be applied in both cell-free and in vivo systems to improve cannabinoid production.

Improved production of cannabinoids. With our designed CBGA synthase in hand (M23), we tested the ability to produce CBGA directly from glucose and OA using the full synthetic biochemistry system, including the PDH bypass (Fig. 1). The 
initial productivity of the system using M23 was $67 \mathrm{mg} \mathrm{L}^{-1} \mathrm{~h}^{-1}$ with a final titer of $744 \pm 34 \mathrm{mg} / \mathrm{L}$ CBGA-100-fold faster and 21fold higher titer than CBGA production using WT $\mathrm{NphB}$ (Fig. 4a). We noted that with the mutant NphB enzyme, maximum titers were reached within $24 \mathrm{~h}$, after which production spontaneously stopped. In contrast, the system with the wild-type enzyme ran continuously for up to 4 days, suggesting enzymes and cofactors remain active and viable for longer periods of time, consistent with prior work ${ }^{26}$. So what is stopping the reaction at the higher titers? We observed that reactions turned cloudy once $\sim 500 \mathrm{mg} / \mathrm{L}$ CBGA was produced. We collected the precipitate and identified a mix of enzymes in the precipitate by sodium dodecyl sulfate polyacrylamide gel electrophoresis (SDS-PAGE) analysis (Supplementary Figure 3), indicating high-levels of CBGA in solution may be causing enzymes to precipitate. We, therefore, sought to continually remove the product in situ during the reaction (a capability difficult to implement in living systems).

Initially a fixed volume nonane overlay was used for each reaction to extract CBGA. Unfortunately, CBGA is more soluble in water than nonane, limiting the amount of CBGA that can be extracted with a simple overlay. We therefore designed a flow system that would capture CBGA from the nonane layer and trap it in a separate buffered reservoir (Fig. 4b). By implementing this flow system we hoped to maintain a lower concentration of CBGA in the reaction vessel to mitigate enzyme precipitation. The flow system indeed improved the final titers to $1.25 \pm 0.07 \mathrm{~g} / \mathrm{L}$, however, enzyme precipitation still occurred at about $24 \mathrm{~h}$.

We next evaluated the system flexibility by replacing $\mathrm{OA}$ with divarinic acid (DA) to produce the precursor of many rare cannabinoids, CBGVA. We first tested whether our designed enzymes would be active with DA as the substrate. Kinetic analysis (Table S5) indicated that M31 effectively prenylates DA, with catalytic efficiencies 15 -fold higher than M23 and 650-fold higher than WT NphB. We, therefore, utilized M31 to produce CBGVA from glucose and DA. As shown in Fig. 4a, CBGVA was produced at a maximum productivity of $\sim 107 \mathrm{mg} \mathrm{L}^{-1} \mathrm{~h}^{-1}$, and reached a final titer of $1.74 \pm 0.09 \mathrm{~g} / \mathrm{L}$, converting $92 \%$ of the added DA to CBGVA. The nonane-flow system was not needed for the production of CBGVA because CBGVA was less potent in precipitating enzymes.

Production of additional cannabinoids. To illustrate the production of other cannabinoids from the central cannabinoids CBGA and CBGVA, we employed CBDA synthase to convert CBGA into CBDA and CBGVA into CBDVA. Conversion of CBGA into CBDA has been demonstrated by several groups ${ }^{17,34-36}$. In our case, we simply transferred the nonane overlay containing CBGA to an aqueous solution containing CBDA synthase, and indeed we were able to convert CBGA into CBDA at a constant rate of $14.4 \pm 0.8 \mathrm{mg} \mathrm{L}^{-1} \mathrm{~h}^{-1} \mathrm{mg}$ total protein ${ }^{-1}$ over the course of 4 days converting $25 \%$ of the CBGA added to CBDA (Fig. 4c). To our knowledge it is not known whether CBGVA can be converted into the rare cannabinoid CBDVA using the CBDA synthase. So we added CBGVA, extracted from the cell-free system, to a reaction containing CBDA synthase. CBDVA was produced (Supplementary Figure 4) by CBDA synthase at a rate of $7.1 \pm 0.1 \mathrm{mg} \mathrm{L}^{-1} \mathrm{~h}^{-1} \mathrm{mg}$ total protein ${ }^{-1}$ for $24 \mathrm{~h}$. We note that the cannabinoid acids can undergo spontaneous decarboxylation or heat induced decarboxylation to ultimately form additional bioactive cannabinoids CBD and cannabidivarin (CBDV). Thus, our system provides opportunities for ultimately producing a wide-variety of cannabinoids.

\section{Discussion}

Our results demonstrate the power and flexibility of a cell-free approach, not only for the production of pure, therapeutically relevant cannabinoids and other prenylated natural products, but a

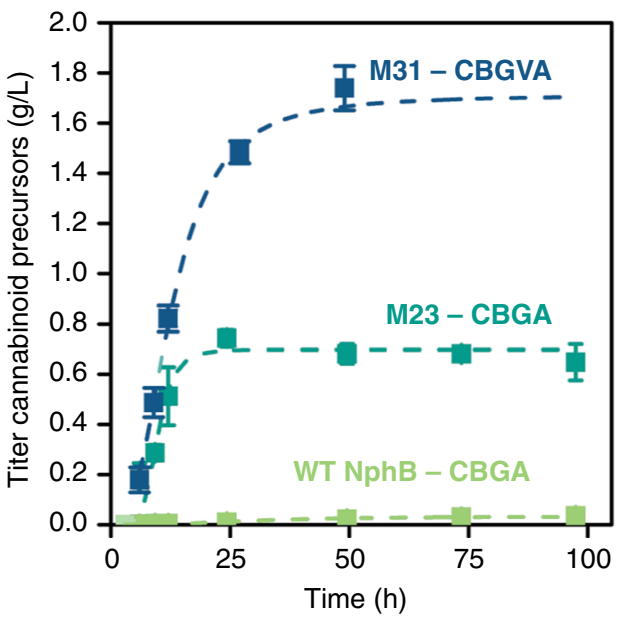

b

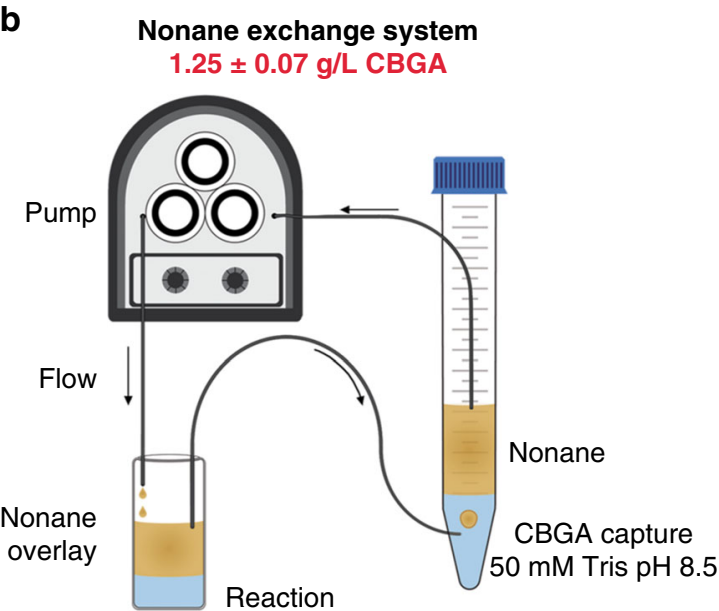

C

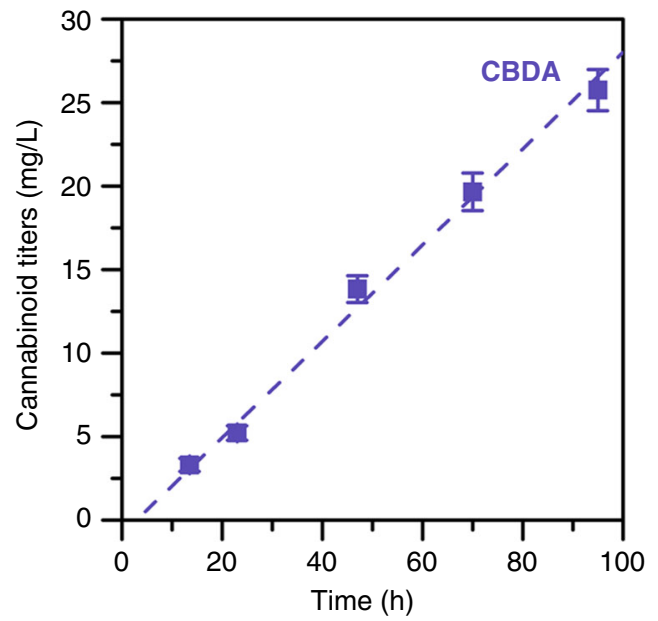

Fig. 4 Evaluation of the cell-free prenylation system for the production of various cannabinoids. a The cell-free enzymatic production (from glucose) of cannabinoid precursors over time. CBGA production using M23 is shown in the dark aqua trace and WT NphB in the light green trace. The production of CBGVA using M31 is shown in the dark blue trace. The concentration of WT, M23, and M31 NphB was fixed at $0.5 \mathrm{mg} / \mathrm{mL}$ (biological replicates, $n=3$ ). b Using a nonane-flow CBGA capture system, we were able to obtain a higher titer of CBGA $(1.2 \mathrm{~g} / \mathrm{L})$. The nonane layer was exchanged using a peristaltic pump, which circulated the nonane in the direction indicated by the arrows. c Production of CBDA over time using CBDAS (biological replicates, $n=3$ ). All error ranges are the standard deviation. Source data for Fig. 4a, c are provided as a Source Data file 
for bio-derived chemicals in general. Freedom from worries about cell viability allowed us to focus on pathway optimization rather than minimizing GPP toxicity, while the lack of a cell membrane barrier freed us to design a system with added aromatic molecules, which would not be possible in cells. Moreover, we could flexibly change the input from OA to DA to target rare cannabinoids without redesigning an entire pathway. Finally, it was straightforward to identify and focus our efforts on fixing the bottleneck steps. When we started this project we were only able to produce $9 \mathrm{mg} / \mathrm{L}$ of CBGA using the monoterpene pathway developed by Korman et al. ${ }^{26}$. By introducing the PDH bypass and optimizing for cofactors, enzymes and environmental factors we were able to increase those titers to $132 \mathrm{mg} / \mathrm{L}$. To improve titers further we engineered the NphB prenyltransferase, which further increased titers to $600 \mathrm{mg} / \mathrm{L}$ of CBGA. The final bottleneck was enzyme stability in the presence of CBGA, so by limiting the CBGA in the reaction vessel, we increased the titer to $1.25 \mathrm{~g} / \mathrm{L}$ of CBGA, nearly a 140 -fold improvement. Solutions were quickly implemented due to speedy design-build-test cycles, rapidly yielding results that far exceed published results using living cells. Like all new technology, the current system will need additional technical developments to become commercially viable, but our results suggest that synthetic biochemistry can become a realistic option for producing bio-based chemicals.

\section{Methods}

Chemicals and reagents. Yeast hexokinase and Corynebacterium glutamicum catalase were purchased from Sigma Aldrich. Aerococcus viridians pyruvate oxidase was purchased from A.G. scientific. All cofactors and reagents were purchased from either Sigma Aldrich or Thermo Fisher Scientific, with the exception of OA, which was purchased from Santa Cruz Biotechnology and divarinic acid, which was purchased from Toronto Research Chemicals.

Cloning and purification of enzymes. The NphB gene was purchased as a gene block from IDT DNA, and cloned into a pET 28(+) vector using the Gibson Assembly method. The gene block sequences are provided in Supplementary Data 1 . The remaining enzymes were amplified from genomic DNA or a plasmid, and cloned into pET28(+) using the same Gibson assembly method. The primer sequences used for amplification in this work are listed in Supplementary Table 6. All plasmids were transformed into BL21(DE3) Gold, and enzymes expressed in LB media with $50 \mu \mathrm{g} / \mathrm{mL}$ kanamycin. One litre cultures were inoculated with $2 \mathrm{~mL}$ of a saturated culture in the same media, and grown to an $\mathrm{OD}_{600}$ of $0.5-0.8$ at $37^{\circ} \mathrm{C}$. The cultures were induced with $1 \mathrm{mM}$ IPTG, and expressed at $18^{\circ} \mathrm{C}$ for $16 \mathrm{~h}$. The cells were harvested by centrifugation at $2500 \times \mathrm{g}$, and resuspended in $\sim 20 \mathrm{~mL}$ lysis buffer: $50 \mathrm{mM}$ Tris [pH 8.0], $150 \mathrm{mM} \mathrm{NaCl}$, and $10 \mathrm{mM}$ imidazole. The cells were lysed using an Emulsiflex instrument. The lysate was clarified by centrifugation at $20,000 \times g$, and the supernatant was batch bound to $1 \mathrm{~mL} \mathrm{NiNTA}$ resin for $30 \mathrm{~min}$ at $4{ }^{\circ} \mathrm{C}$. The resin was transferred to a gravity flow column. The resin was washed with 10 column volumes of wash buffer: $50 \mathrm{mM}$ Tris [pH 8.0], $150 \mathrm{mM} \mathrm{NaCl}$, and $10 \mathrm{mM}$ imidazole. The protein was then eluted with 2 column volumes of elution buffer: $50 \mathrm{mM}$ Tris [pH 8.0], $150 \mathrm{mM} \mathrm{NaCl}, 250 \mathrm{mM}$ imidazole, and $30 \%$ (v/v) glycerol. Enzymes were flash frozen in elution buffer using liquid $\mathrm{N}_{2}$, and the enzyme stocks were stored at $-80^{\circ} \mathrm{C}$.

PDH cell-free reactions. The PDH reactions were assembled in two parts. First the cofactors and substrates were combined in one tube, and the enzymes were combined in another. The reactions were initiated by mixing the cofactors and enzymes in a final volume of $200 \mu \mathrm{L}$. The final substrate and co-factor concentrations were as follows: $500 \mathrm{mM}$ glucose, $1 \mathrm{mM}$ 1,6 fructose bisphosphate, $4 \mathrm{mM}$ ATP, $0.5 \mathrm{mM} 2,3$ bisphosphoglycerate, $0.5 \mathrm{mM} \mathrm{NAD}^{+}, 1.5 \mathrm{mM}$ CoA, $1.5 \mathrm{mM} \mathrm{NADP}^{+}, 0.5 \mathrm{mM}$ TPP, $6 \mathrm{mM} \mathrm{MgCl}_{2}, 10 \mathrm{mM} \mathrm{KCl}, 50 \mathrm{mM}$ Tris [pH 8.0] and $20 \mathrm{mM}$ phosphate buffer [pH 8.0], $5 \mathrm{mM}$ glutathione, and $0.5-5 \mathrm{mM} 1,6 \mathrm{DHN}$. The enzyme amounts added to the reaction can be found in Supplementary Table 1 (PyOx and PTA were not added to these reactions). The reactions were quenched at $24 \mathrm{~h}$.

PDH activity assays. PDH was assayed for activity in the presence of several aromatic polyketides. The vehicle control was $1 \%$ ethanol, and the activity was compared to an assay without the aromatic polyketides. The final reaction volume was $200 \mu \mathrm{L}$, and contained $2 \mathrm{mM} \mathrm{NAD}+, 2 \mathrm{mM} \mathrm{CoA}, 1 \mathrm{mM} \mathrm{TPP}, 5 \mathrm{mM} \mathrm{MgCl}_{2}$, $5 \mathrm{mM} \mathrm{KCl}, 50 \mathrm{mM}$ Tris $\mathrm{pH} 8.0$, and $5 \mu \mathrm{L}$ of $1.25 \mathrm{mg} / \mathrm{mL}$ PDH. The reactions were set up in a 96-well plate. The aromatic polyketides (dissolved in ethanol) were added to a final concentration of $1 \mathrm{mM}$ and the ethanol control was added to a final concentration of $1 \%(\mathrm{v} / \mathrm{v})$. The plate was incubated at room temperature for $10 \mathrm{~min}$, and the reactions were initiated with $10 \mu \mathrm{L}$ of $100 \mathrm{mM}$ pyruvate. The absorbance at $340 \mathrm{~nm}$ was monitored for 10 min using an M200 spectrometer. Because the aromatic molecules had a background absorbance at $340 \mathrm{~nm}$, the reactions were blanked using the reaction mixture and aromatic molecule, but instead of initiating the reaction with pyruvate, water was added. The initial rates were determined using the initial slope of a linear fit. The amount of $\mathrm{NADH}$ produced per unit time was calculated using Beer's law, and the extinction coefficient of $6.22 \times 10^{3} \mathrm{M}^{-1} \mathrm{~cm}^{-1}$. Reactions were performed in triplicate, and the average value and standard error were calculated.

PyOx/PTA cell-free reactions. The $\mathrm{PyOx} / \mathrm{PTA}$ reactions were assembled in two pieces. First the cofactors and substrates were combined in one tube, and the enzymes were combined in another. The final co-factor and substrate concentrations in the $200 \mu \mathrm{L}$ reaction were as follows: $500 \mathrm{mM}$ glucose, $1 \mathrm{mM} \mathrm{1,6}$ fructose bisphosphate, $4 \mathrm{mM}$ ATP, $0.5 \mathrm{mM}$ 2,3 bisphosphoglycerate, $0.5 \mathrm{mM} \mathrm{NAD}^{+}, 1.5$ $\mathrm{mM}$ CoA, $3 \mathrm{mM}$ mM NADP ${ }^{+}, 0.5 \mathrm{mM}$ TPP, $6 \mathrm{mM} \mathrm{MgCl}_{2}, 10 \mathrm{mM} \mathrm{KCl}, 50 \mathrm{mM}$ Tris, and $50 \mathrm{mM}$ phosphate buffer [pH 8.0]. The amount of enzyme added to each reaction is detailed in Supplemental Table 1. The cofactors and enzymes were mixed to initiate the reaction, and a $500 \mu \mathrm{L}$ nonane overlay was added to the top. The reactions were incubated at room temperature shaking gently on a gel shaker.

When the aromatic substrate was the varied component $0.5-5 \mathrm{mM}$ of the aromatic substrate was added to the reaction, and the reactions were quenched at $24 \mathrm{~h}$. When time was the varied component, $5 \mathrm{mM}$ of 1,6 DHN was added, and separate reactions were quenched at $\sim 12,24,48$, and $72 \mathrm{~h}$.

Conditions for the olivetolate and divarinic acid reactions (produced CBGA and CBGVA, respectively) were altered slightly. Optimization of the cannabinoid pathway showed that the same titers could be achieved with less glucose, so we reduced the glucose concentration to $150 \mathrm{mM}$ (we did not test lower glucose concentrations). Additionally, increasing the $\mathrm{NADP}^{+}$concentration to $6 \mathrm{mM}$ and decreasing the ATP concentration to $1 \mathrm{mM}$ led to higher titers of CBGA. The olivetolate concentration was set at $5 \mathrm{mM}$. The amount of $\mathrm{NphB}$ added to the reaction was variable. The data shown in Fig. $2 \mathrm{c}$ utilized $1.5 \mathrm{mg} / \mathrm{mL} \mathrm{NphB}$, and the reactions were quenched at $\sim 4,8,14,24,48,72$, and $96 \mathrm{~h}$. The data shown in Fig. 4 a was achieved with $0.5 \mathrm{mg} / \mathrm{mL}$ of WT NphB and M23 and M31 (for divarinic acid), and reactions were quenched at $\sim 6,9,12,24,48,72$, and $96 \mathrm{~h}$.

The conditions were identical to the method above with the following exceptions, the final concentration of the aromatic substrates was $1 \mathrm{mM}$ and the initial glucose concentration was $150 \mathrm{mM}$. Additionally, the final concentration of the prenyl-transferase was $1 \mathrm{mg} / \mathrm{mL}$, and we tested AtaPT, NovQ, and NphB with apigenin, daidzein, genistein, naringenin, and resveratrol. We also tested $\mathrm{NphB}$ with olivetol, olivetolate, and 1,6 DHN. The reactions were quenched at $24 \mathrm{~h}$.

Quenching reactions. To quench the reactions, the aqueous and organic layer were transferred to a $1.5 \mathrm{~mL}$ microcentrifuge tube. The reaction vial was washed with $200 \mu \mathrm{L}$ of ethyl acetate, which was then pooled with the reaction in the microcentrifuge tube. The samples were vortexed for 5-10 s and then centrifuged for $3 \mathrm{~min}$ at $16,060 \times g$. The organic layer was removed, and the remaining aqueous layer was extracted two additional times with $200 \mu \mathrm{L}$ of ethyl acetate. For each sample the organic extract was pooled, and then evaporated using a vacuum centrifuge. The samples were redissolved in methanol for HPLC analysis. Due to the observed protein precipitation, the CBGA reactions shown in Fig. 4a were extracted in the presence of $0.12 \mathrm{~g}$ of urea (solid), to facilitate the extraction of CBGA. This was unnecessary for the WT NphB CBGA data in Fig. 2c because the proteins did not precipitate.

Quantification of products. The reactions were fractionated by reverse phase chromatography on a $\mathrm{C} 18$ column $(4.6 \times 100 \mathrm{~mm})$ using a Thermo Ultimate 3000 HPLC. The column compartment temperature was set to $40^{\circ} \mathrm{C}$, and the flow rate was $1 \mathrm{~mL} / \mathrm{min}$. The compounds were separated using a gradient elution with water $+0.1 \%$ TFA (solvent A) and acetonitrile $+0.1 \%$ TFA (solvent B) as the mobile phase. Solvent B was held at $20 \%$ for the first min. Then solvent B was increased to $95 \%$ B over $4 \mathrm{~min}$, and $95 \%$ B was then held for 3 min. The column was then re-equilibrated to $20 \% \mathrm{~B}$ for three min, for a total run time of $11 \mathrm{~min}$.

The cannabinoids (CBGA, CBDA, and CBDVA) were quantified using an external calibration curve derived from an analytical standard purchased from Sigma Aldrich. The 5-p-1,6-DHN and CBGVA nuclear magnetic resonance (NMR) samples were used to generate an external calibration curve because authentic standards were not available (see below). A known concentration of the standard was dissolved in water, and then extracted using the method detailed above.

Quantify prenyl-products without authentic standards. Due to the lack of authentic standards for the prenyl-products prenyl-apigenin, prenyl-daidzein, prenyl-naringenin, prenyl-genistein, prenyl-resveratrol, and prenyl-olivetol, we quantified the prenyl-products based on substrate consumption. To generate a standard curve, serial dilutions of each aromatic substrate were subjected to the reaction mix, but to prevent product formation the prenyl-transferase was left out 
We used liquid chromatography-mass spectrometry to quantify the amount of substrate consumed by the reaction compared to the standard curve.

Electrospray ionisation time-of-flight measurements were carried out on a Waters LCT-Premier XE Time of Flight Instrument controlled by MassLynx 4.1 software (Waters Corporation, Milford, MA). The instrument was equipped with the Multi Mode Ionization source operated in the electrospray mode. A solution of Leucine Enkephalin (Sigma Chemical, L9133) was used in the LockSpray to obtain accurate mass measurements. Samples were infused using direct loop injection on a Waters Acquity UPLC system. Samples were separated on a Waters Acquity UPLC system using an Acquity BEH C18 $1.7 \mu \mathrm{m}$ column $(50 \times 2.1 \mathrm{~mm})$ and were eluted with a gradient of $30-95 \%$ solvent B over $10 \mathrm{~min}$ (solvent A: water, solvent B: acetonitrile, both with $0.2 \%$ formic acid (vol/ $/ \mathrm{vol})$ ). Mass spectra were recorded from a mass of $300-2000 \mathrm{Da}$.

NMR spectroscopy. NMR spectroscopy was used to identify prenyl-products, and quantify 5-p-1,6-DHN. The PyOx/PTA cell-free system was used to produce prenyl-DHN. A total of $200 \mu \mathrm{L}$ reactions were pooled, and extracted three times with an equivalent amount of nonane and then the nonane was evaporated. The product of the reactions was suspended in $500 \mu \mathrm{L}$ of deuterated methanol $\left(\mathrm{CD}_{3} \mathrm{OD}\right)$, with $2 \mathrm{mM} \mathrm{1,3,5-trimethoxybenzene} \mathrm{(TMB)} \mathrm{as} \mathrm{an} \mathrm{internal} \mathrm{standard.}$ Spectra were collected on an AV400 Bruker NMR spectrometer. The amount of the prenylated compound in the sample was determined with reference to the internal TMB standard. We compared the proton signal from TMB (3H, singlet) at 6.05 $\mathrm{ppm}$ with an aromatic proton corresponding to $5-\mathrm{p}-1,6-\mathrm{DHN}(1 \mathrm{H}$, doublet) at $7.27 \mathrm{ppm}$.

NMR was also used to identify the product of the enzymatic system with divarinic acid as the aromatic substrate. The PyOx/PTA system was set up as detailed above, and the reactions were quenched at $24 \mathrm{~h}$. The reactions were extracted as detailed above (under the subheading: Quenching Reactions), and analyzed on the HPLC. There was a new major peak at 6.7 min that we predicted to be the prenylated divarinic acid. We HPLC purified the peak, removed the solvent, and redissolved the pure component in $600 \mu \mathrm{L}$ of $\mathrm{CD}_{3} \mathrm{OD}$. A proton spectrum collected with an AV500 Bruker NMR spectrometer was compared to a proton spectrum published by Shoyama et al. ${ }^{37}$ for CBGVA to confirm that CBGVA was the main product. Based on the report by Shoyama et al. the study by Bohlmann et al. ${ }^{38}$, we conclude that the prenylation of divarinic acid occurs at the $\mathrm{C} 3$ carbon of divarinic acid. Shoyoma et al. ${ }^{37}$ published the chemical shifts of CBGVA in $\mathrm{CD}_{3} \mathrm{OD}$, so by direct comparison of our NMR spectra to the published chemical shifts we conclude that we produced CBGVA. This is further supported by the work conducted by Bohlmann, which suggests that if the prenylation occurred at the C5 site, we would observe a proton with a chemical shift around $5.8 \mathrm{ppm}$, which we did not observe, Supplementary Figure 11

Rosetta design to modify the binding pocket of NphB. We placed olivetolate in the active site of $\mathrm{NphB}$ in six different starting positions denoted as Olivetolate P1-6 in Table S2. We ran ROSETTA 5 times for each olivetolate position for a total of 30 designs. The mutations predicted in each design are listed in Table S2. For each olivetolate position we chose a consensus set of mutations (i.e., the most frequently chosen residue) to evaluate further: Consensus Group A through $\mathrm{F}$ (Table S2). We then sought to evaluate the relative importance of each ROSSETTA suggested mutation. For each Consensus Group, we set the mutations back to WT residue, one at a time, and used ROSETTA to calculate the change in energy score (see Table S3). Those that caused the largest change in energy were deemed to be the most important mutants to include in the library for experimental testing.

To model the OA, we took the 4MX.sdf 3-D structure of olivetolate from the 5B09 crystal structure and added hydrogen atoms to the structure assuming $\mathrm{pH} 7$ using Open Babel 2.3.139. A rotamer library was generated for OA using the Bio Chemical Library (BCL) molecule: Conformer Generator 3.5 using the PDB library ${ }^{40}$. Finally, the aromatic bonds were manually annotated into the file before generating the parameter file read by Rosetta using the script main/source/python/ public/molfile to params.py in the Rosetta 3.7 release. The parameter file for geranyl s-thioldiphosphate (GST) was generated without a rotamer library using the GST.sdf file from the 1ZB6 crystal structure. The OA molecule was then manually placed into the co-crystal structure of NphB with GST and DHN (1ZB6) with the DHN and crystallographic waters removed using pymol. The OA was placed in 6 different positions in the active site with the plane of the olivetolate aromatic ring parallel to the GST alkyl tail and the desired prenylation site 3.7 angstroms away from the eventual carbocation mirroring the placement of DHN in the 1ZB6 crystal structure. Residues 49, 162, 213, 224, 232, 233, 234, 271, 286, and 288 were allowed to be any amino acid during the Rosetta design with other sidechains held in a fixed position and the backbone fixed. The designed residues were in direct contact with the olivetolate and not in direct contact with GST. The fixed backbone script main/source/bin/fixbb.static.linuxgccrelease from the Rosetta 3.7 release was run with the all possible rotamers (-ex4), using the input sidechains (-use_input_sc), sidechains minimized after design (minimize_sidechains), the linear memnode interaction graph (-linmem_ig 10), and both with and without the ligand weighted score function (-score:weights ligand). From the identical starting point each design was run five times using the -nstruct input.

Initial NphB mutant library screening. For screening of the initial library, we performed small scale expression and purifications. In total, $25 \mathrm{~mL}$ of LB media with $50 \mu \mathrm{g} / \mathrm{mL}$ of kanamycin was inoculated with $25 \mu \mathrm{L}$ of a saturated culture of BL21 DE3 Gold harboring the NphB expression plasmid. The cultures were incubated at $37^{\circ} \mathrm{C}$ until the $\mathrm{OD}_{600}$ reached $0.4-0.6$. The expression of the $\mathrm{NphB}$ constructs were induced with the addition of $1 \mathrm{mM}$ IPTG, followed by incubation for $18 \mathrm{~h}$ at $18^{\circ} \mathrm{C}$. Cells were harvested by centrifugation at $2500 \times g$. The pellets were resuspended in $500 \mu \mathrm{L}$ of lysis buffer: $50 \mathrm{mM}$ [Tris $\mathrm{pH} 8.0$ ], $150 \mathrm{mM} \mathrm{NaCl}$, and $5 \mathrm{mM}$ imidazole and lysed by sonication. The cell lysate was clarified by centrifugation at $20,000 \times g$ for $10 \mathrm{~min}$ at $4{ }^{\circ} \mathrm{C}$, and the supernatant was incubated at $4{ }^{\circ} \mathrm{C}$ with $50 \mu \mathrm{L}$ of NiNTA resin. A 96-well spin column plate was used to purify the NphB constructs. The supernatant/resin was applied to the column and centrifuged for $2 \mathrm{~min}$ at $500 \times \mathrm{g}$. A total of $500 \mu \mathrm{L}$ of lysis buffer was then added, and the plate was centrifuged again for $1 \mathrm{~min}$ at $500 \times \mathrm{g}$. The protein was eluted using $200 \mu \mathrm{L}$ of elution buffer (50 mM Tris [pH 8.0], $150 \mathrm{mM} \mathrm{NaCl}, 250 \mathrm{mM}$ imidazole and $30 \%(\mathrm{v} / \mathrm{v})$ glycerol).

The enzymes were assayed under the following conditions: $2.5 \mathrm{mM}$ geranylpyrophosphate, $5 \mathrm{mM}$ olivetolate, $5 \mathrm{mM} \mathrm{MgCl}, 50 \mathrm{mM}$ Tris $\mathrm{pH} 8.0, \sim 0.1 \mathrm{mg} / \mathrm{mL}$ $\mathrm{NphB}$ mutant in a final volume of $100 \mu \mathrm{L}$. All enzymes were first diluted to $0.5 \mathrm{mg} /$ $\mathrm{mL}$ using elution buffer so the final concentration of imidazole was the same in each reaction. The reactions were incubated for $12 \mathrm{~h}$ at room temperature, then extracted 3 times with $100 \mu \mathrm{L}$ of ethyl acetate. The organic extract was pooled for each reaction and the solvent was removed using a vacuum centrifuge. The samples were redissolved in $100 \mu \mathrm{L}$ of methanol and subjected to HPLC analysis.

Focused NphB mutant library screening. For the focused library, we performed $1 \mathrm{~L}$ scale expression and purification of the $\mathrm{NphB}$ constructs as described above. The enzymes were assayed under the following conditions: $2.5 \mathrm{mM}$ GPP, $5 \mathrm{mM}$ olivetolate, $5 \mathrm{mM} \mathrm{MgCl}_{2}, 50 \mathrm{mM}$ Tris $\mathrm{pH} 8.0$, and $\sim 1 \mathrm{mg} / \mathrm{mL}$ of NphB enzyme in a final volume of $100 \mu \mathrm{L}$. The reactions were incubated at room temperature for $1 \mathrm{~h}$. A total of $40 \mu \mathrm{L}$ of each reaction was quenched in $80 \mu \mathrm{L}$ of acetonitrile. The samples were centrifuged for $5 \mathrm{~min}$ at $16,060 \times g$, to remove precipitated proteins. The supernatant was analyzed using HPLC as described above.

Enzyme kinetic parameters. The reactions were set up under the following conditions: $50 \mathrm{mM}$ Tris [pH 8.0], $2.5 \mathrm{mM}$ GPP, $5 \mathrm{mM} \mathrm{MgCl}_{2}, \sim 27 \mu \mathrm{M}$ enzyme, and olivetolate or divarinic acid was varied from 0.1 to $6 \mathrm{mM}$ in a final volume of $200 \mu \mathrm{L}$. A total of $40 \mu \mathrm{L}$ of the reaction was quenched in $80 \mu \mathrm{l}$ acetonitrile $+0.1 \%$ TFA, at the time intervals detailed below. The reactions were centrifuged for 5 min at $13,000-16,060 \times g$ to pellet the protein, and the supernatant was analyzed using the HPLC method detailed above. The initial rate was plotted vs the concentration of substrate, and fit with the Michaelis-Menten equation to determine the kinetic parameters $k_{\text {cat }}$ and $K_{\mathrm{M}}$ (OriginPro). Each Michaelis-Menten curve was performed in triplicate. The average and standard deviation of the kinetic parameters are reported. The time courses with olivetolate as the substrate were as follows: for WT, $\mathrm{M} 1, \mathrm{M} 10$, and M30 the time course was 3, 6, 9, and $12 \mathrm{~min}$. For M25 the reactions were quenched at 1,2, 4, and $8 \mathrm{~min}$, and for M31 the reactions were quenched at 1 , 2,4 , and $6 \mathrm{~min}$.

The conditions were altered slightly to characterize the constructs with divarinic acid as the substrate. For M31, the time course was $0.5,1,1.5$, and $2 \mathrm{~min}$. For M23, the time course was $5,10,15$, and $20 \mathrm{~min}$, and for WT NphB the time course was 8 16,24 , and $32 \mathrm{~min}$. The enzyme concentration for the mutants was $\sim 27 \mu \mathrm{M}$, and the concentration of WT NphB was $\sim 35 \mu \mathrm{M}$.

GC-MS characterization of isomer profile for WT NphB and M23. Samples were dissolved in $200 \mu \mathrm{L}$ of ethyl acetate. Gas chromatography (GC)-MS measurements were carried out using an Agilent Model 7693 Autosampler, 7890B Gas Chromatograph, and 7250 Q-TOF Mass Selective Detector in the Electron Ionization mode. Sample injection was carried out in split mode with inlet temperature set to $280^{\circ} \mathrm{C}$. Separation was carried out on an Agilent HP5-MS column with dimensions $30 \mathrm{~m} \times 250 \times 0.25 \mu \mathrm{m}$. Ultra High Purity Grade He (Airgas) was used as carrier gas with the flow set to $1.1 \mathrm{~mL} / \mathrm{min}$ in constant flow mode. The initial oven temperature was set to $120^{\circ} \mathrm{C}$ for $1 \mathrm{~min}$ followed by a $20^{\circ} \mathrm{C} / \mathrm{min}$ ramp to a final temperature of $300^{\circ} \mathrm{C}$ which was maintained for $4 \mathrm{~min}$. A 3.0 min solvent delay was used. EI energy was set to $15 \mathrm{eV}$. The MSD was set to scan the $50-500 \mathrm{~m} / \mathrm{z}$ range. Data collection and analysis were performed using Mass Hunter Acquisition and Qualitative Analysis software (Agilent).

Due to the increased temperature of the GC inlet, CBGA undergoes spontaneous decarboxylation as described by Radwan et al ${ }^{41}$, resulting in an $\mathrm{M}+$ ion at $316 \mathrm{~m} / \mathrm{z}$. The retention time corresponding to the $316 \mathrm{~m} / \mathrm{z}$ ion for the CBGA standard was $10.48 \mathrm{~min}$

Nonane-flow system for the extraction of CBGA from solution. A PyOx/PTA reaction was set up as detailed above. A $500 \mu \mathrm{L}$ nonane overlay was added to the reaction in a $2 \mathrm{ml}$ glass vial which was covered with 2 layers of breathable cell culture film. Two 18-gauge needles were inserted into a $15 \mathrm{~mL}$ falcon tube at the $\sim 750 \mu \mathrm{L}$ mark and the $3.5 \mathrm{~mL}$ mark. Luer locks to tubing connectors were connected to the needles and Viton tubing was connected to the other end of the luer lock. Eighteen-gauge needles were connected to the other end of the tubing via a luer lock connector and inserted through the mesh covering so they were only touching the nonane layer and not the reaction. In total, $2 \mathrm{~mL}$ of Tris buffer 
[pH 8.5] was added to the $15 \mathrm{~mL}$ conical tube, and $6 \mathrm{~mL}$ of nonane was added. The nonane was pumped through the system using a peristaltic pump $(\sim 1 \mathrm{~mL} / \mathrm{min})$ such that the nonane flowed from the top of the reaction, through the buffered solution ( $\sim 18 \mathrm{~cm}$ tubing). The nonane pumped into the reservoir separated into the top layer of the $15 \mathrm{~mL}$ conical tube. The nonane from the top of the $15 \mathrm{~mL}$ conical tube was pumped into the top of the reaction vial $(\sim 55 \mathrm{~cm}$ tubing). This essentially diluted the CBGA throughout the system driving the diffusion of CBGA into the nonane layer and out of the reaction.

Cloning CBDAS. A gene block of cannabidiolic acid synthase (CBDAS) with the signaling peptide was ordered from IDT codon optimized for Pichia pastoris. The signal sequence was removed by PCR amplifying from the 28th residue of the protein sequence (NPREN...) through the end of the protein, with overhangs compatible with the pPICZa vector. The PCR product was cloned into the pPICZa vector digested with EcoRI and $\mathrm{XbaI}$ using the Gibson cloning method. The product of the assembly reaction was transformed into BL21 Gold (DE3) cells, and a clone with the correct sequence was isolated. The plasmid was digested with PmeI for $2 \mathrm{~h}$, and then purified using the Qiagen PCR purification protocol. The plasmid was transformed into Pichia pastoris X33 using electroporation. Immediately following electroporation, the cells were incubated in $1 \mathrm{~mL}$ of cold $1 \mathrm{M}$ sorbitol and 1 $\mathrm{mL}$ of YPD media without shaking for $2 \mathrm{~h}$. The cells were plated on YPDS plates with $500 \mu \mathrm{g} / \mathrm{mL}$ of zeocin. Colonies were screened using PCR for the presence of the CBDAS gene between the AOX1 promoter and terminator. For screening, the colonies were resuspended in $15 \mu \mathrm{L}$ of sterile water and $5 \mu \mathrm{L}$ of the resuspended colony was transferred into a PCR tube with $0.2 \%$ SDS. The samples were heated for $10 \mathrm{~min}$ at $99^{\circ} \mathrm{C}$, and then $1 \mu \mathrm{L}$ was used as the template for PCR. Six colonies with positive colony PCR hits were screened for the expression of CBDAS.

CBDAS-expression test. The six colonies were grown overnight at $30^{\circ} \mathrm{C}$ in $25 \mathrm{~mL}$ of buffered complex glycerol medium (BMGY) to obtain a saturated culture. The overnight cultures were used to inoculate a $25 \mathrm{~mL}$ culture in BMGY media and grown to an OD of $\sim 2$. The cells were harvested by centrifugation at $2000 \times g$ for $10 \mathrm{~min}$. The cell pellet was resuspended in $90 \mathrm{~mL}$ of buffered minimal methanol yeast extract media, and incubated at $30^{\circ} \mathrm{C}$ for 5 days. Each day, $1 \mathrm{~mL}$ of the culture was removed for SDS-PAGE analysis, and $500 \mu \mathrm{L}$ of methanol was added to the remaining culture. On day 3 the cultures were screened for CBDAS activity. The 1 $\mathrm{mL}$ culture samples were centrifuged to pellet the cells $(16,060 \times g, 5 \mathrm{~min})$. A $50 \mu \mathrm{L}$ of the media was used in a subsequent activity assay, and the remainder of the media was stored at $-80^{\circ} \mathrm{C}$ in addition to the cell pellet. The assay conditions were as follows: $100 \mu \mathrm{L}$ of $200 \mathrm{mM}$ citrate buffer, $100 \mu \mathrm{M} \mathrm{CBGA}, 5 \mathrm{mM} \mathrm{MgCl}, 5 \mathrm{mM}$ $\mathrm{KCl}, 1 \mathrm{mM} \mathrm{FAD}$, and $50 \mu \mathrm{L}$ of the expression media in a final volume of $200 \mu \mathrm{L}$. The reactions were incubated overnight at room temperature and then extracted 3 times with $200 \mu \mathrm{L}$ of ethyl acetate. The ethyl acetate extractions were pooled for each sample, and removed using a vacuum centrifuge. The samples were resuspended in $200 \mu \mathrm{L}$ of methanol and analyzed by HPLC. All clones produced active CBDAS.

The culture from three clones $(\sim 300 \mathrm{~mL}$ total), was collected to obtain CBDAS activity. The cells were pelleted by centrifuging at $\sim 3000 \times g$ for $20 \mathrm{~min}$ at $4{ }^{\circ} \mathrm{C}$. Then the supernatant was passed through a $0.22 \mu \mathrm{m}$ filter. The media was concentrated and buffer exchanged into $100 \mathrm{mM}$ citrate buffer $\mathrm{pH} 5.0$ using a 50,000 molecular weight cut-off protein concentrator from Millipore.

Production of CBDVA and CBDA. To convert the precursors CBGA and CBGVA into CBDA and CBGVA, respectively, a secondary reaction was set up with CBDAS. To produce CBDA, a PyOx/PTA enzymatic system was set up as detailed above to produce CBGA. After $24 \mathrm{~h} 200 \mu \mathrm{L}$ of the nonane overlay from the CBGA reaction was transferred to a CBDAS reaction vessel. In the aqueous layer: $50 \mathrm{mM}$ Hepes [pH 7.0], $5 \mathrm{mM} \mathrm{MgCl}_{2}, 5 \mathrm{mM} \mathrm{KCl}, 25 \mu \mathrm{M}$ FAD, $0.1 \mathrm{mg} / \mathrm{mL}$ CBDAS concentrate. The reaction was incubated at $30^{\circ} \mathrm{C}$ with gentle shaking. Reactions were quenched at $12,24,48,72$, and $96 \mathrm{~h}$.

To produce CBDVA, HPLC purified CBGVA was converted to CBDVA using CBDAS. The final reaction volume was $200 \mu \mathrm{L}$, with $50 \mathrm{mM}$ Hepes [pH 7.0], $5 \mathrm{mM}$ $\mathrm{MgCl}_{2}, 5 \mathrm{mM} \mathrm{KCl}, 25 \mu \mathrm{M} \mathrm{FAD}$ and $0.1 \mathrm{mg} / \mathrm{mL}$ (total protein) of CBDAS concentrate. A $200 \mu \mathrm{L}$ nonane overlay was added, and the reactions were incubated at $30^{\circ} \mathrm{C}$ with gentle shaking. The reactions were quenched at $\sim 24,48,72$, and $96 \mathrm{~h}$.

Reporting summary. Further information on experimental design is available in the Nature Research Reporting Summary linked to this article.

\section{Data availability}

All data generated or analyzed in this study are in this published article and its Supplementary materials. The authors will make every reasonable effort to provide data and materials described herein upon request. A reporting summery for this article is available as a Supplementary Information file. The source data underlying Figs. 2A-D, 3B, C, 4A, C, Supplementary Figures 2 and 4 and Supplementary Table 5 are provided as a Source Data file.

Received: 13 November 2018 Accepted: 10 January 2019 Published online: 04 February 2019

\section{References}

1. Chen, X., Mukwaya, E., Wong, M.-S. \& Zhang, Y. A systematic review on biological activities of prenylated flavonoids. Pharm. Biol. 52, 655-660 (2014).

2. Andre, C. M., Hausman, J.-F. \& Guerriero, G. Cannabis sativa: the plant of the thousand and one molecules. Front. Plant Sci. 7, 19 (2016).

3. Markovà, J. et al. Sativex ${ }^{\oplus}$ as add-on therapy Vs. further optimized first-line ANTispastics (SAVANT) in resistant multiple sclerosis spasticity: a doubleblind, placebo-controlled randomised clinical trial. Int. J. Neurosci. 13, 1-10 (2018).

4. Tramèr, M. R. et al. Cannabinoids for control of chemotherapy induced nausea and vomiting: quantitative systematic review. Br Med J 323, 16 (2001)

5. Devinsky, O. et al. Cannabidiol in patients with treatment-resistant epilepsy: an open-label interventional trial. Lancet Neurol. 15, 270-278 (2016).

6. Ben Amar, M. Cannabinoids in medicine: a review of their therapeutic potential. J. Ethnopharmacol. 105, 1-25 (2006).

7. Hazekamp, A. et al. Preparative Isolation of Cannabinoids from Cannabis sativa by centrifugal partition chromatography. J. Liq. Chromatogr. Relat. Technol. 27, 2421-2439 (2004).

8. Lewis, M. M., Yang, Y., Wasilewski, E., Clarke, H. A. \& Kotra, L. P. Chemical profiling of medical Cannabis extracts. ACS Omega 2, 6091-6103 (2017).

9. Dethe, D. H., Erande, R. D., Mahapatra, S., Das, S. \& B., V. K. Protecting group free enantiospecific total syntheses of structurally diverse natural products of the tetrahydrocannabinoid family. Chem. Commun. 51, 2871-2873 (2015).

10. Shultz, Z. P., Lawrence, G. A., Jacobson, J. M., Cruz, E. J. \& Leahy, J. W. Enantioselective total synthesis of Cannabinoids-a route for analogue development. Org. Lett. 20, 381-384 (2018).

11. Tischer, S. \& Metz, P. Selective C-6 prenylation of flavonoids via europium (III)-catalyzed Claisen rearrangement and cross-metathesis. Adv. Synth. Catal. 349, 147-151 (2007).

12. Lussier, F.-X., Colatriano, D., Wiltshire, Z., Page, J. E. \& Martin, V. J. J. Engineering microbes for plant polyketide biosynthesis. Comput. Struct. Biotechnol. J. 3, e201210020 (2012).

13. Tan, Z., Clomburg, J. \& Gonzalez, R. Synthetic pathway for the production of olivetolic acid in Escherichia coli. ACS Synth. Biol. 7, 1886-1896 (2018).

14. Sarria, S., Wong, B., Martín, H. G., Keasling, J. D. \& Peralta-Yahya, P. Microbial synthesis of Pinene. ACS Synth. Biol. 3, 466-475 (2014).

15. Gagne, S. J. et al. Identification of olivetolic acid cyclase from Cannabis sativa reveals a unique catalytic route to plant polyketides. Proc. Natl Acad. Sci. 109, 12811 (2012).

16. Zirpel, B., Degenhardt, F., Martin, C., Kayser, O. \& Stehle, F. Engineering yeasts as platform organisms for cannabinoid biosynthesis. J. Biotechnol. 259, 204-212 (2017).

17. Zirpel, B. et al. Optimization of $\Delta 9$-tetrahydrocannabinolic acid synthase production in Komagataella phaffii via post-translational bottleneck identification. J. Biotechnol. 272-273, 40-47 (2018).

18. Lu, F., Smith, P. R., Mehta, K. \& Swartz, J. R. Development of a synthetic pathway to convert glucose to hydrogen using cell free extracts. Int. J. Hydrog. Energy 40, 9113-9124 (2015).

19. Hold, C., Billerbeck, S. \& Panke, S. Forward design of a complex enzyme cascade reaction. Nat. Commun. 7, 12971 (2016).

20. Schwander, T., Schada von Borzyskowski, L., Burgener, S., Cortina, N. S. \& Erb, T. J. A synthetic pathway for the fixation of carbon dioxide in vitro. Science 354, 900 (2016).

21. Zhang, Y.-H. P. Production of biofuels and biochemicals by in vitro synthetic biosystems: Opportunities and challenges. Ind. Biotechnol. Tools Appl. 33, 1467-1483 (2015)

22. Swartz, J. Developing cell-free biology for industrial applications. J. Ind. Microbiol. Biotechnol. 33, 476-485 (2006).

23. Perez, J. G., Stark, J. C. \& Jewett, M. C. Cell-free synthetic biology: engineering beyond the cell. Cold Spring Harb. Perspect. Biol. 8, a023853 (2016).

24. Schmidt-Dannert Claudia. The future of biologically inspired next-generation factories for chemicals. Microb. Biotechnol. 10, 1164-1166 (2017).

25. You, C. et al. An in vitro synthetic biology platform for the industrial biomanufacturing of myo-inositol from starch. Biotechnol. Bioeng. 114, 1855-1864 (2017).

26. Korman, T. P., Opgenorth, P. H. \& Bowie, J. U. A synthetic biochemistry platform for cell free production of monoterpenes from glucose. Nat. Commun. 8, 15526 (2017).

27. Opgenorth, P. H., Korman, T. P. \& Bowie, J. U. A synthetic biochemistry molecular purge valve module that maintains redox balance. Nat. Commun. 5, 4113 (2014)

28. Opgenorth, P. H., Korman, T. P., Iancu, L. \& Bowie, J. U. A molecular rheostat maintains ATP levels to drive a synthetic biochemistry system. Nat. Chem. Biol. 13, 938 (2017).

29. Kumano, T., Richard, S. B., Noel, J. P., Nishiyama, M. \& Kuzuyama, T. Chemoenzymatic syntheses of prenylated aromatic small molecules using Streptomyces prenyltransferases with relaxed substrate specificities. Bioorg. Med. Chem. 16, 8117-8126 (2008). 
30. Chen, R. et al. Molecular insights into the enzyme promiscuity of an aromatic prenyltransferase. Nat. Chem. Biol. 13, 226 (2016).

31. Ozaki, T., Mishima, S., Nishiyama, M. \& Kuzuyama, T. NovQ is a prenyltransferase capable of catalyzing the addition of a dimethylallyl group to both phenylpropanoids and flavonoids. J. Antibiot. 62, 385 (2009).

32. Kuzuyama, T., Noel, J. P. \& Richard, S. B. Structural basis for the promiscuous biosynthetic prenylation of aromatic natural products. Nature 435, 983 (2005).

33. Fellermeier, M. \& Zenk, M. H. Prenylation of olivetolate by a hemp transferase yields cannabigerolic acid, the precursor of tetrahydrocannabinol. FEBS Lett. 427, 283-285 (1998).

34. Zirpel, B., Kayser, O. \& Stehle, F. Elucidation of structure-function relationship of THCA and CBDA synthase from Cannabis sativaL. J. Biotechnol. 284, 17-26 (2018).

35. Taura, F. et al. Cannabidiolic-acid synthase, the chemotype-determining enzyme in the fiber-type Cannabis sativa. FEBS Lett. 581, 2929-2934 (2007).

36. Taura, F., Morimoto, S. \& Shoyama, Y. Purification and characterization of cannabidiolic-acid synthase from Cannabis sativa L.: biochemical analysis of a novel enzyme that catalyzes the oxidocyclization of cannabigerolic acid to cannabidiolic acid. J. Biol. Chem. 271, 17411-17416 (1996).

37. Shoyama, Y., Hirano, H., Makino, H., Umekita, N. \& Nishioka, I. Cannabis. X. The isolation and structures of four new propyl cannabinoid acids, tetrahydrocannabivarinic acid, cannabidivarinic acid, cannabichromevarinic acid and cannabigerovarinic acid, from Thai Cannabis, 'Meao Variant'. Chem. Pharm. Bull. 25, 2306-2311 (1977).

38. Bohlmann, F. \& Hoffmann, E. Cannabigerol-ähnliche verbindungen aus Helichrysum umbraculigerum. Phytochemistry 18, 1371-1374 (1979).

39. O’Boyle, N. M. et al. Open Babel: an open chemical toolbox. J. Chemin-. 3, 33 (2011).

40. Kothiwale, S., Mendenhall, J. L. \& Meiler, J. BCL: Conf: small molecule conformational sampling using a knowledge based rotamer library. J. Cheminform. 7, 47 (2015).

41. Radwan, M. M. et al. Isolation and characterization of new cannabis constituents from a high potency variety. Planta Med. 74, 267-272 (2008).

\section{Acknowledgments}

The authors thank members of the Bowie lab for helpful comments. This work was supported by DOE grants DE-FC02-02ER63421 and DE-AR0000556 to J.B., and an NIH National Research Service Award 5T32GM008496 to M.V.

\section{Author contributions}

M.V., T.K., and J.B. conceived of the project. M.V. performed the bulk of the experiments along with N.W., M.V., T.K., and D.B. developed enzyme designs. G.K. and R.T. assisted with mass spectrometry and NMR experiments and analysis, respectively. All authors contributed to data interpretation and writing the manuscript.

\section{Additional information}

Supplementary Information accompanies this paper at https://doi.org/10.1038/s41467019-08448-y.

Competing interests: T.K. and J.B. are founders of a company, Invizyne Technologies, that seeks to develop cell-free chemical production. The remaining authors declare no competing interests.

Reprints and permission information is available online at http://npg.nature.com/ reprintsandpermissions/

Journal peer review information: Nature Communications thanks Olive Kayser and the other anonymous reviewer(s) for their contribution to the peer review of this work. Peer reviewer reports are available.

Publisher's note: Springer Nature remains neutral with regard to jurisdictional claims in published maps and institutional affiliations.

(c) (i) Open Access This article is licensed under a Creative Commons Attribution 4.0 International License, which permits use, sharing, adaptation, distribution and reproduction in any medium or format, as long as you give appropriate credit to the original author(s) and the source, provide a link to the Creative Commons license, and indicate if changes were made. The images or other third party material in this article are included in the article's Creative Commons license, unless indicated otherwise in a credit line to the material. If material is not included in the article's Creative Commons license and your intended use is not permitted by statutory regulation or exceeds the permitted use, you will need to obtain permission directly from the copyright holder. To view a copy of this license, visit http://creativecommons.org/ licenses/by/4.0/.

(C) The Author(s) 2019 